\title{
Effect of harvesting practices, lifting time, curing methods, and irrigation on quercetin content in onion (Allium cepa L.) cultivars
}

\author{
Eun Young Ko', Kavita Sharma², Shivraj Hariram Nile ${ }^{1 *}$ \\ ${ }^{1}$ Department of Bio-resources and Food Science, College of Life and Environmental Sciences, Konkuk University, Seoul- 143-701, Republic of \\ Korea, ${ }^{2}$ School of Chemical Engineering, Yeungnam University, Gyeongsan, 712-749, Republic of Korea
}

\section{A B S T R A C T}

\begin{abstract}
This study is aimed to measure the quercetin and quercetin glucoside content in onion cultivars with respect to pre and postharvest treatments including lifting time, drip irrigation, curing and forced curing on quercetin content in nineteen onions (Allium cepa L.) cultivars were studied. The quercetin contents ranged from 0.011 to $4.109 \mathrm{mg} / 100 \mathrm{mg}$ dry weight basis among nineteen studied onion varieties. The highest amount of quercetin was detected in red varieties ('Colossus'), lowest in white varieties ('ISI 2120'), meanwhile yellow variety T-M-8-4 exhibited higher quercetin content compared to other yellow and white varieties. The amount of quercetin glucosides content in different parts of onion follows an increasing order from inner to outer scales. It has been observed that, outer scales of onions contain 3.5 times higher quercetin glucosides than the inner ones. There is no direct relation between the numbers of drip irrigation on the contents of quercetins; compared to the control group (with regular irrigation after every week). Similarly, Lifting time had minor effects on quercetin content among the selected onion cultivars. Cultivar differences in quercetin content were significant but not consistent during the time of this study. During forced curing of skin, as well as the peeled onion, the total quercetin content of cured onion decreased as compared to non-cured control samples. This study indicates that, the onion genotypes provided to be the best way to increase quercetin content in onion bulb.
\end{abstract}

Keywords: Curing; Harvesting; Irrigation; Lifting times; Onion; Quercetin

\section{INTRODUCTION}

Onions have been widely used throughout the world as a flavoring vegetable as well as a traditional and folk medicine. Onion extracts and the isolated bioactive compounds from onion has wide range of biological effects including antioxidant, antiplatelet, antidiabetic, anticarcinogenic, antiasthmatic, antimicrobial, anti-inflammatory and antibiotic effects on human health (Griffiths et al., 2002; Sharma, et al., 2015). Onion comprises two important groups of phytochemicals; flavonoids and the alk(en)yl cysteine sulphoxides, that are proved to be have beneficial effects to human health. The bioactive flavonols which are rich in onions are having potential antioxidant activity and found in high amount in many foods and vegetables. Onions contains 16 different kinds of flavonols in different forms including quercetin and its aglycones and glycosylated derivatives, isorhamnetin and kaempferol (Beesk et al.,
2010). It is well known that quercetin has been found with pronounced effect on various allergies, asthma, arthritis, cancer, coronary heart disease, diabetic complications, gout, and neurodegenerative disorders (Häanninen et al., 2000; Soobrattee et al., 2006; Hegarty et al., 2000; Kempuraj et al., 2006). The flavonols are often found in high concentrations in the skin of most the onions, where they impart their yellow/brown colour, unless concealed by the red pigment, such as anthocyanin. In dried red onion, the concentration of quercetin was found to be as high as $2.1 \% \mathrm{w} / \mathrm{w}$ (Nile and Park, 2013). The total content of quercetin in onion is $300 \mathrm{mg} / \mathrm{kg}$, which is considerably higher than in many other fruits and vegetables (Hollman and Arts, 2000). The flavonols in onions are also found in the onion flesh, scale and tissues where it accounts for a yellow coloration if their concentrations are high level or a cream hue at lower concentrations. Compared to yellow onions the white skinned onions, garlic, and leek contains very low amount

\footnotetext{
*Corresponding author:

Shivraj Hariram Nile, Department of Bio-resources and Food Science, College of Life and Environmental Sciences, Konkuk University, Seoul-143-701, Republic of Korea. E-mail: nileshivraj@gmail.com
} 
of flavonols and so unable to impart coloration in food sample (Yoo et al., 2010). The concentration or amount of flavonols gradually increases from inner to outer scales in onions (Lee et al., 2008). Onions contains 93\% of quercetin derivative viz; diglucoside and monoglucoside of total content of flavonols (Lombard et al., 2005). The flavonoid content in onion is strongly influenced by extrinsic factors such as variations in variety, cultivation and field curing (Mogren et al., 2006), scales, size (Chu et al., 2000), light (Higashio et al., 2005), storage (Jang et al., 2013) and processing (Kevin et al., 2005). It has previously studied that nitrogen levels and temperature can influence onion flavonoid content and quality (Coolong et al., 2003; Randle 2000). A decrease in soil nitrogen concentration due to excess irrigation may be associated with an increase in total quercetin concentration (Mogren et al. 2006). The quercetin content mainly depends on lifting time as early lifting ( $50 \%$ fallen leaves or less) for onions affect late sprouting after long term storage with reduced yield. Also early lifting effect on quality parameters of onions including lighter color, lower quercetin content and trace amount of nutrients (Grevsen and Sorensen, 2004; Wright et al., 2001). Flavonol content in onions is significant by curing which may be forced curing but this phenomenon is corelated or dependent on time of cultivation and cultivar type (Mogren et al. 2006; Chope et al. 2012). Various lights effects inclduing sunlight, UV-light or blue lights are important factors which directly help to incresed accumulation of flavonol derivatives (Mogren et al., 2006; Ko, et al., 2014). Quercetin aglycone concentration varies with onion scale as it is higher in amount in innermot scale compared to outer most scale and modrate to middle scales. Due this variying amount of aglycone concentration will not contribute essentially or effect on total quercetin content in onnion bulbs as it is lower inside the bulb as compared to the exterior scales. Beesk et al. (2010), and Lee and Mitchell (2011) repoterd same phenomenon for quercetin aglycone concentration in scale-to-scale distribution for onions. Also the storage conditions and temprature affect on quercetin content in various onion varieties depending on the color of onions and varieties but only few studies reported the effect of curing and storage with different temperature and quercetin content (Chope et al., 2012; Sharma, et al., 2015). The aim of present study is to measure the quercetin content in onion cultivars with pre and postharvest treatments on the basis of different cultivars, number of drip irrigation cycles provided, different scales, and forced curing for onions.

\section{MATERIALS AND METHODS}

\section{Plant material}

The nineteen onion varieties which were selected for this study which are cultivated in May -June, 2015 from the Bioenergy Center (Muan County, Jeolla-Namdo, Korea) in June, 2015 (Table 1).

\section{Onion scales}

The distribution of quercetin glucosides among scales of onion bulbs has been studied. The bulbs were vertically chopped with the knife from the top to the basal portion of the onions. The seven different scales ( $\mathrm{s} 1=$ first scale; s2 = second; $\mathrm{s} 3=$ third; $\mathrm{s} 4=$ forth; $\mathrm{s} 5=$ fifth; $\mathrm{s} 6=$ sixth; s7 $=$ seventh (inner layers) of onions were chopped into

Table 1: Characteristics of onion varieties

\begin{tabular}{|c|c|c|c|c|c|c|}
\hline Varieties & ID & Color & Ripening & ${ }^{\text {bBulb index }}$ & Transplanted date (Year 2015) & Harvested date (Year 2015) \\
\hline ISI 2120 & ISI 2120 & White & Precocious & 89 & November 2 & June 5 \\
\hline Shinsunhwang & Sh & Yellow & Precocious & 93 & November 2 & May 21 \\
\hline Yeonsinhwang & Ye & Yellow & Precocious & 89 & November 2 & May 21 \\
\hline Sunpower & Su & Yellow & Mid and late & 98 & November 11 & June 3 \\
\hline Marusino 330 & $\mathrm{Ma}$ & Yellow & Precocious & 81 & November 2 & May 21 \\
\hline MON-1-29 & $1-29$ & Yellow & Precocious & 82 & November 2 & May 18 \\
\hline MON-1-12 & $1-12$ & Yellow & Precocious & 82 & November 2 & May 21 \\
\hline T-M-8-4 & $8-4$ & Yellow & Precocious & 96 & November 12 & June 5 \\
\hline Wolgawang & Wol & Yellow & Precocious & 99 & November 12 & June 5 \\
\hline Goldengaenggo & Go & Yellow & Precocious & 97 & November 13 & June 5 \\
\hline KO & KO & Yellow & Late & 94 & November 12 & June 3 \\
\hline KM & KM & Yellow & Late & 94 & November 12 & June 3 \\
\hline Worldking & Wor & Yellow & Late & 96 & November 12 & June 5 \\
\hline Red Grano & $R G$ & Red & Precocious & 74 & November 12 & June 3 \\
\hline Red Burgandy & RB & Red & Precocious & 81 & November 12 & June 3 \\
\hline Rosalie & Ro & Red & Precocious & 73 & November 12 & June 3 \\
\hline Chunjoojuck & $\mathrm{Ch}$ & Red & Precocious & 89 & November 5 & June 3 \\
\hline All red & Ol & Red & Precocious & 84 & November 12 & June 5 \\
\hline Colossus & Co & Red & Precocious & 90 & November 12 & June 3 \\
\hline
\end{tabular}

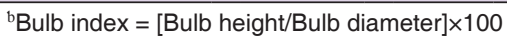


small pieces and freeze-dried with the help of a lyophilizer and quercetin content was determined. For further studies only the outer layer (which has maximum quercetin content) of onions were selected and chopped into small pieces and freeze-dried with the help of a lyophilizer and quercetin content was determined.

\section{Lifting times}

The lifting time of the onion is usually determined by the percentage of fallen leaves. The same criteria were applied for this experiment. The first and second lots of onions were obtained from the field after $10 \%$ and $40 \%$ of the leaves of onion plants had dropped, respectively. The third and fourth lots of onions were harvested from the $10^{\text {th }}$ and $20^{\text {th }}$ days (A: $10 \%$ fallen leaves, B: $40 \%$ fallen leaves, C: $10^{\text {th }}$ days of $100 \%$ fallen leaves, D: $20^{\text {th }}$ days of $100 \%$ fallen leaves) after 100\% leaf drop (Mogren et al., 2006).

\section{Drip irrigation}

In general, the irrigation plays an important role in plant growth and development. In the case of onions, the frequency of irrigation influences the rotting, sprouting, physiological weight loss and quercetin content in onions. To study the changes in quercetin content by drip irrigation, the experiments were carried out from the $2^{\text {nd }}$ week of May until mid-July of 2013 as indicated A: 10\% fallen leaves, B: 40\% fallen leaves, C: $10^{\text {th }}$ days of $100 \%$ fallen leaves, D: $20^{\text {th }}$ days of $100 \%$ fallen leaves. The land area and amount of drip irrigation were kept constant throughout the whole treatment. The first lot of experiments was treated with one time of irrigation only and onions were harvested. The other lots were treated with drip irrigation according to the evapotranspiration rate and drip irrigation provided data available during the experimental periods. There is no extra irrigation in case of control onions crops. The date and the number of irrigation are summarized in Table 2.

\section{Forced curing system}

Field curing is a common practice used for the long term storage of onions. Curing was done for 15 days after lifting and the onions were kept on the field in the windrows for drying. In the present study, from the each onion varieties the seven uniformed sized bulbs were transferred to the growth chamber and maintained at $36^{\circ} \mathrm{C}$ for 3 consecutive days. Physiological changes have been observed after the forced curing treatment. Onion bulbs had developed

Table 2: The dates and time of irrigation (Year 2015)

\begin{tabular}{lcccc}
\hline Sample & Times & Date & Area & Amount \\
\hline W1 & 1 & 5.11 & $3.0 \mathrm{~m}^{2}$ & $60 \mathrm{~L}$ \\
W2 & 2 & 5.115 .21 & $3.0 \mathrm{~m}^{2}$ & $60 \mathrm{~L}$ \\
W3 & 3 & $5.11,5.16,5.21$ & $3.0 \mathrm{~m}^{2}$ & $60 \mathrm{~L}$ \\
W5 & 5 & $5.11,5.16,5.19,5.23,5.26$ & $3.0 \mathrm{~m}^{2}$ & $60 \mathrm{~L}$ \\
\hline
\end{tabular}

papery skin with color change to red and the neck become dry and tight.

\section{Extraction of quercetin}

Similar-sized onion bulbs from all selected varieties were considered for the analysis of quercetin (Table 1). The top dried layer, root, unused parts of the onion bulbs, outer dried skin, and other inedible outer portions were removed, and the each scales separately used for the analysis. The samples were freeze dried, lyophilized, and kept at $-70^{\circ} \mathrm{C}$ prior to use. The HPLC analysis consisted of, $100 \mathrm{mg}$ of lyophilized onion tissue was extracted with $2 \mathrm{~mL}$ of $80 \%$ methanol by sonication (30s), and the mixture was centrifuged for $5 \mathrm{~min}\left(5,000 \mathrm{~g}\right.$ at $\left.4^{\circ} \mathrm{C}\right)$. The step was repeated five times, and the supernatants were collected in a $5 \mathrm{~mL}$ bottle (Mogren et al., 2006).

\section{HPLC analysis of quercetin}

The onion extracts were filtered through a 0.45 micro filter unit (Whatman syringe-filter PVDF) and then transferred to a $1 \mathrm{~mL}$ vial for HPLC analysis. HPLC analytical condition was the same as described previously by Ko, et al., (2014). The HPLC system was Agilent 1100 (Agilent, Palo Alto, USA). An Agilent Eclipse XDB-C 18 analytical column $(5 \mu \mathrm{m}$ particle size; $250 \times 0.6 \mathrm{~mm})$ was employed for analysis. UV absorbance was measured at a wavelength of $365 \mathrm{~nm}$ (Lee et al., 2008)

\section{Quantification}

The commercial quercetin and its derivatives including quercetin-3,4'-diglucoside, and quercetin-4'-glucoside were used as reference compounds (Genay Cedex, France). During HPLC analysis the quercetin sample was injected in 3 replicates and the average peak areas were selected at $365 \mathrm{~nm}$ and quercetin concentration was calculated by comparing the retention time and UV-vis spectra, in the 200-500 $\mathrm{nm}$ range using reference compound peak area. Individual peaks were clearly checked for purity to avoid and exclude any interfering peaks which may contribute for false result. The flavonoid standards were dissolved in $80 \%$ or $100 \% \mathrm{MeOH}$ at several concentrations and standard curves were obtained for quantitative analysis. Quercetin, quercetin-3, 4'-diglucoside, and quercetin4'-glucoside of the samples was identified based on the retention time, and the concentrations of each compound were calculated from the standard curve of authentic compounds (Table 3). Simple linear and logarithmic correlation analysis was used to calculate correlation level in quercetin, quercetin-3,4'-diglucoside, and quercetin4'-glucoside variables. The correlations between onion and total quercetin glucosides (Quercetin, quercetin-3, 4'-diglucoside, and quercetin-4'-glucoside) were high which was correlated using standards of quercetin and quercetin glucosides. 


\section{Statistical analysis}

The linear model procedure (GLM) of 2005 SAS package (Version 9.2, SAS Inst. Inc. Cary, N. C., USA) were used for statistical analysis. Mean separation within columns by Duncan's multiple range test at $P=0.05$.

\section{RESULTS AND DISCUSSION}

\section{Quercetin and its glucosides content in different onion varieties}

In present study, nineteen varieties of different colored onions were evaluated for quercetin contents. The content of quercetin glucosides was found to be ranged from 0.011 to $4.109 \mathrm{mg} / 100 \mathrm{mg}$ on dry weight basis among the nineteen varieties. These results are consistent and comparable with the previous results (Ko, et al., 2014; Rodríguez et al., 2008) that the red variety contains a high quercetin content comparing to yellow and white varieties. The 'colossus' (Red type), Chunjoojuck (Red type) and T-M8-4 (Yellow type) showed the highest amount of quercetin glucosides (4.109, 2.8 and $2.6 \mathrm{mg} / 100 \mathrm{mg} \mathrm{dw}$, respectively) whereas 'ISI 2120' (White type) had the lowest amount of quercetin glucosides $(0.011 \mathrm{mg} / 100 \mathrm{mg} \mathrm{dw})$. Quercetin content was not detected almost in all studied varieties but the content of quercetin diglucosides was higher than those of monoglucosides in all the studied varieties. Fig. 1 represents the quercetin glucoside contents among the different varieties. In case of quercetin diglucosides and monoglucosides, the red varieties showed 5:2 ratios and it was slightly higher than that off white varieties with $5: 1$ ratio, and the yellow varieties with 3:1 ratio. The correlation between quercetin 3, 4'-diglucosides and quercetin4'glucoside was reasonable $\left(R^{2}=0.986\right)$, thus suggesting that activities of glucosyltransferases, which transform quercetin to quercetin-4'-glucoside and quercetin-4'-glucoside to quercetin-3, 4'-diglucoside were different (Fig. 2). There are about 20 flavonols found in onion species and the main flavonol glucosides present in onions (Allium cepa) are the monoglucoside quercetin 4'-O-glucoside (OMG) and the diglucoside quercetin 3,4'-O-diglucoside (QDG) which account for $85 \%$ to $90 \%$ (Beesk et al., 2010; Bonaccorsi et al., 2008; Yoo et al., 2010) of total flavonoids and up to $97 \%$ of total quercetin (Yoo et al., 2010) in onion. However, the amount of quercetin glucosides can differ significantly between the various cultivars (Caridi et al., 2007). Red and yellow cultivars have been shown to possess very high concentrations of quercetin glucosides in contrast to white onion cultivars where only traces of the flavonols can be found. Quercetin glucosides (QMG and QDG) were present in high amounts in the inner (QDG) and middle parts (QMG) of the onion bulb whereas quercetin and QMG dominated in the outer scale (Beesk et al., 2010) These results coincide with the finding of the activities of region
Table 3: Calibration curve equations of the three flavonoid standards

\begin{tabular}{lcc}
\hline Flavonoids & \multicolumn{1}{c}{ Equation } & $\boldsymbol{R}^{2}$ \\
\hline Quercetin-3,4'-diglucoside & $\mathrm{x}=(\mathrm{y}+48.912) / 11818$ & 0.9995 \\
Quercetin-4'-glucoside & $\mathrm{x}=(\mathrm{y}-860.02) / 33148$ & 0.9955 \\
Quercetin & $\mathrm{y}=(\mathrm{x}-1906.7) / 45145$ & 0.9994 \\
\hline
\end{tabular}

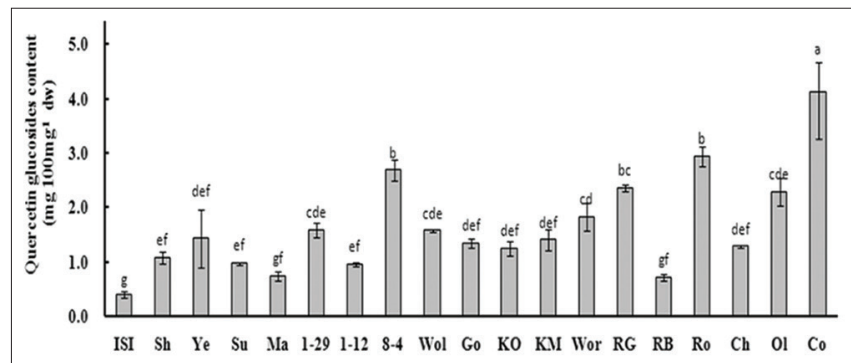

Fig 1. Total quercetin glucosides in different varieties. Vertical bars indicate the standard errors. Significant differences at $P=0.05\left(^{*}\right)$ within the time after harvesting were indicated by letters.

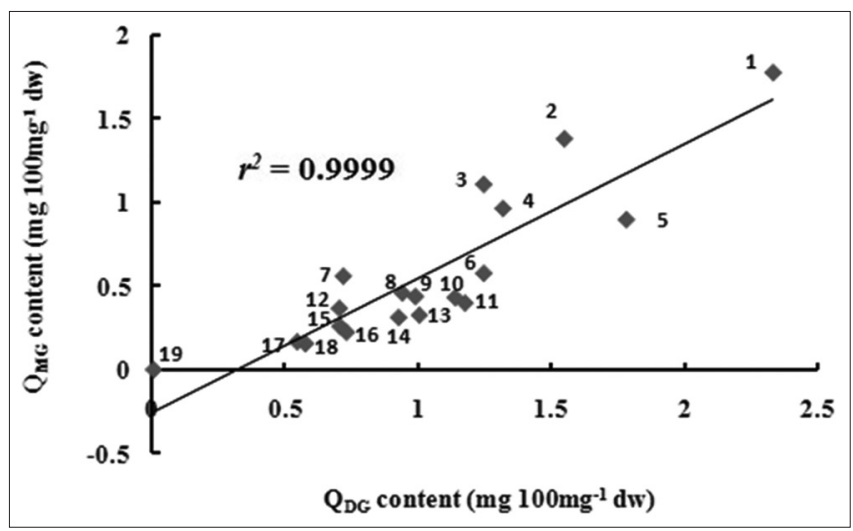

Fig 2. Correlation between quercetin 3,4'-diglucoside $\left(Q_{D G}\right)$ and quercetin 4'-glucoside $\left(Q_{M G}\right)$ in different varieties (19:ISI 2120, 12:Shinsunhwang, 9:Yeonsinhwang, 15:Sunpower, 18:Marusino 330, 11:MON-1-29, 16:MON-1-12, 5:T-M-8-4, 10:Wolgawang, 13: Goldengaenggo, 14:KO, 8:KM, 6:Worldking, 3:Red Grano, 17:Red Burgandy, 2:Rosalie, 7:Chunjoojuck, 4:Ollled, 1:Colossus).

specific quercetin glucosyltransferases activities reported in onions (Bonaccorsi et al., 2008; Yoo et al., 2010) where the glucosyltransferase activity was found higher in the inner than in the outer scales. Onion contains wide range of flavonoids, which may vary depending on cultivar. The order of flavanoid content in different colored onion is variable and found that the red onions contains the highest amount of flavonoids, followed by yellow and white onions (Shon et al., 2004). Yoo et al., 2010 suggested that quercetin in the free form as aglycone was almost absent in the edible parts of onions but it was bound with glucose molecules in the form of quercetin glucosides.

\section{Effect of irrigation and lifting time on quercetin and its glucosides}

The distribution of quercetin and its glucosides was also influenced by the accessibility of light. The content of 
quercetin glucosides did not show significant relations with the number of irrigation (Fig. 3). The samples without external irrigation showed higher contents of quercetin glucosides compared to those were treated with external irrigation. Accordingly, onions react well to irrigation, producing higher yields and good bulb quality with increased watering and irrigation frequency regardless of the type of irrigation system used (Enciso et al., 2009; Kumar et al., 2007; Pejic et al., 2011). For onions, the irrigation criterion for soil water tension varies from 8.5 to $45 \mathrm{kPa}$, depending on the environmental conditions and irrigation system (Shock and Wang, 2011). However, excessive watering can actually reduce yields and dry matter content in onions (Pejic et al., 2011). Lifting time play important role during onion cultivation and directly having effects on quercetin and quercetin derivatives concentration. The late lifting and storage effect on sprouting on quercetin content in onions, the increased quercetin were found during late lifting but sprouting occurs earlier after long-term storage. The annual variation in quercetin content at lifting was significant resulting with higher quercetin content. There is no any significant variation in quercetin glucoside concentration related to early (50\% leaf fall) and late (80\% leaf fall) lifting. The onions harvested on same date and from same row with erect leaves have less amount of quercetin compared to fallen leaves onions with significant content of quercetin glucosides (Mogren et al., 2007a; Mogren et al., 2007b). In this study, it was found that the quercetin glucosides content was higher in onions lifted in the field at the time when $10 \%$ of leaves fallen than the other treatment. Furthermore, there were no much significant differences in quercetin glucosides content in onions were observed in the rest of the experiments which includes the lifting time of $10 \%, 40 \%, 10^{\text {th }}$ day of $100 \%$ and $20^{\text {th }}$ days of $100 \%$ fallen leaves of onions (Fig. 4). It has been reported that early lifting generally improves storability of onions (Fustos 2007). Lifting time plays important role in the sprouting of onions during the storage. Lifting of onion with $50 \%$ of fallen leaves delayed the onset of sprouting by 7 to 10 days; as compared to $80 \%$ fallen leaves onion which stored in cold temperature for 6 to 9 months (Grevsen and Sorensen, 2004). Early and late lifting time also affects the storability; but does affect the dry mass of the onion. Outer dry scale is another important factor which determines the storability and dormancy of the onion (Mogren et al., 2007a). The other criterion which plays a significant role in the flavonoid content is the radiation. It has been reported that the contents of quercetin glucosides were highest when the onions were cured in the field under full sunlight as compared to lifting time and application of nitrogen fertilizer level. Thus the lifting time had minor effects on quercetin content (Mogren et al., 2007b). For scaling studies the variety Colossus were considered as it has been with maximum amount of quercetin content (Fig. 1).

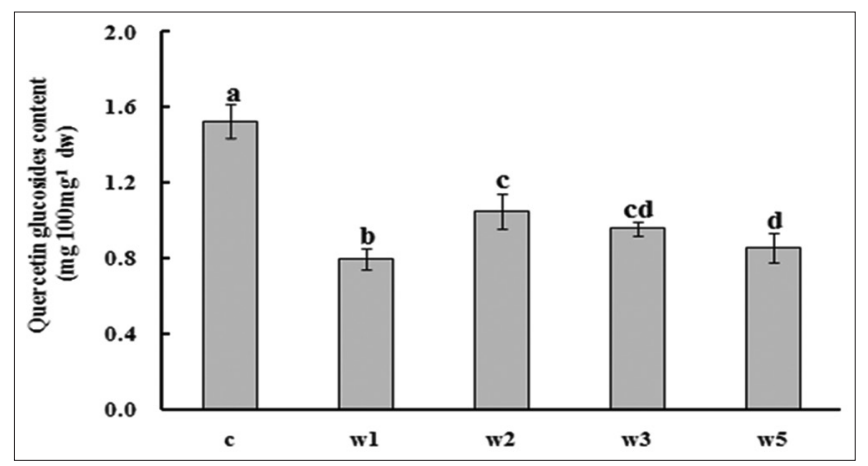

Fig 3. Effect of different irrigation treatment on total quercetin glucosides contents, C: Control, w1: Irrigated one time during bulb maturation, w2: Irrigated two time during bulb maturation, w3: Irrigated three time during bulb maturation, w5: Irrigated five time during bulb maturation.

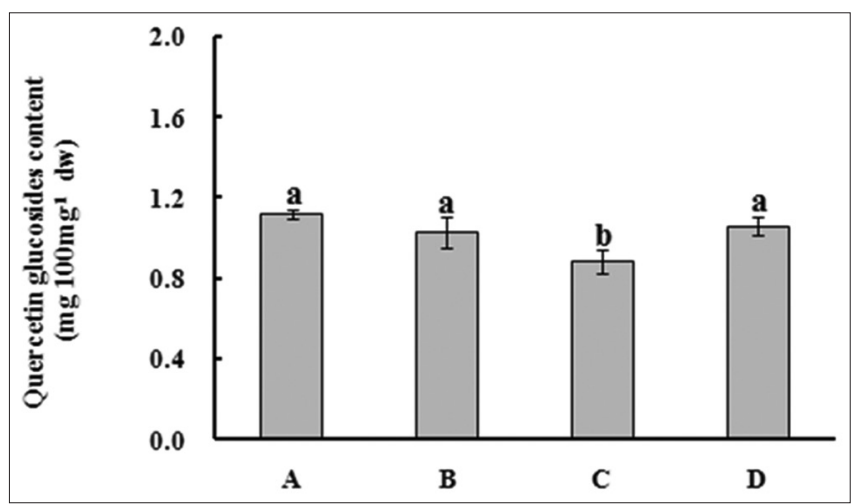

Fig 4. Effect of different lifting times on total quercetin glucosides contents, Vertical bars indicates the standard errors $(n=3)$. Significant differences at $P=0.05\left(^{*}\right)$ within the time after harvesting are indicated by letters. A: $10 \%$ fallen leaves, B: $40 \%$ fallen leaves, C: $10^{\text {th }}$ days of $100 \%$ fallen leaves, D: $20^{\text {th }}$ days of $100 \%$ fallen leaves.

\section{Quercetin and its glucosides content in different scales}

The Fig. 5 shows the quercetin glucosides in different scales of onions. The first scale or the outer scale of the onion contained the highest quercetin glucosides of $1.072 \mathrm{mg} / 100 \mathrm{mg}$ dry weight, whereas the second and third scales contain $0.785 \mathrm{mg} / 100 \mathrm{mg}$ dry weight and $0.449 \mathrm{mg} / 100 \mathrm{mg}$ dry weight, respectively. Forth scale contained the lowest quercetin glucosides as compared to the rest of the scales. Fifth scale contains a slightly higher amount of total quercetin as compared to the sixth and the seventh, which is about $0.34 \mathrm{mg} / 100 \mathrm{mg}$ dry weight. When the outer and inner scales in peeled onion were compared, a 3.5 time increase in quercetin glucosides in outer scales than inner scales was observed. Outer scales had a relatively higher ratio of quercetin monoglucosides to diglucosides than inner scales and overall concentration of quercetin monoglucosides is less than diglucosides. These results are similar to the previously reported results; according to them the amounts of flavonoids in different parts of onions follow an increasing order from the outer to middle and to inner scales. Distribution of flavonoids was not uniform, and it depends on the quantity of light 
exposure and the enzyme participating in the metabolism of onions. Highest concentration of quercetin glucosides in outer scales also helps the onion plants from the attack of pathogens and other kind of environmental stress. Many studies revealed that the concentration of quercetin and quercetin derivatives in gradually increasing order from lower part (root end) to upper part of onions (stem end) and near about $90 \%$ of the total quercetin of each scale was confined to the epidermal tissue, and the rest in the storage tissue (Lee et al., 2008; Chu et al., 2000). In forced curing, the analysis was done separately with the skin and the peeled onion. Both of the results were compared with a control sample. The total quercetin glucosides content of forced curing of skin and peeled onion decreased as compared to those of the control sample (Fig. 6).

\section{Effect of peeling on quercetin and its glucosides}

The quercetin glucosides were deglucosylated to quercetin, which was shown by HPLC analysis of peeled onion. The averaged total quercetin glucosides content in control and forced curing onions are $0.968 \mathrm{mg} / 100 \mathrm{mg}$ dry weight and

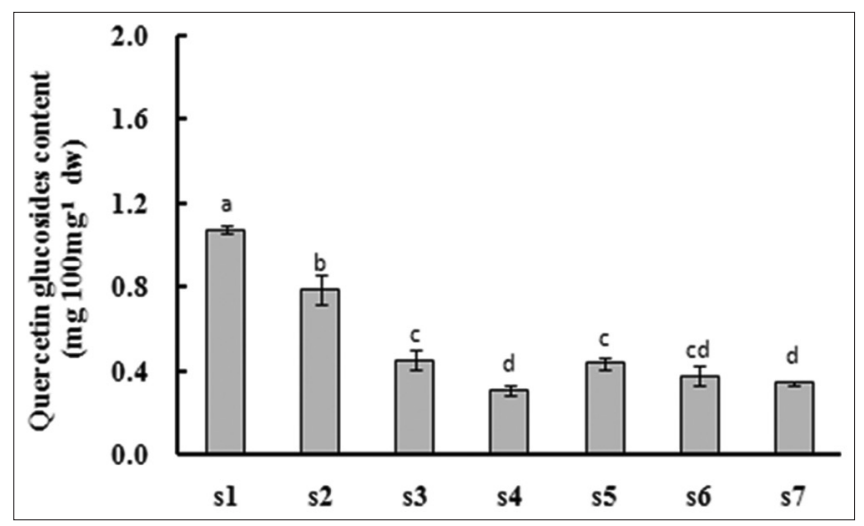

Fig 5. Total quercetin glucosides in different peeled onion scales, Vertical bars indicate the standard errors $(n=3)$. Significant differences at $P=0.05\left(^{*}\right)$ within the time after harvesting are indicated by letters. $\mathrm{s} 1$ = first scale; $\mathrm{s} 2$ = second; $\mathrm{s} 3$ = third; $\mathrm{s} 4$ = forth; $\mathrm{s} 5=$ fifth; $\mathrm{s} 6$ = sixth; s7 $=$ seventh (inner layers).

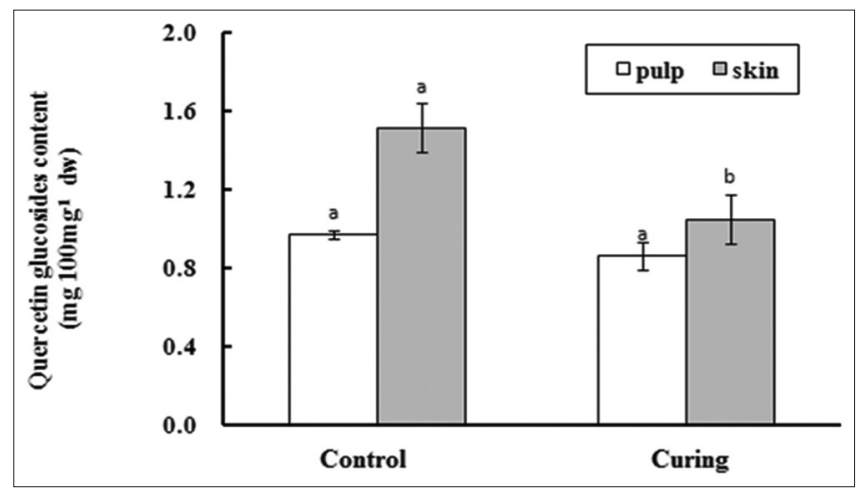

Fig 6. Effect of forced curing treatment on total quercetin glucosides in peeled onion and skin of onion. Vertical bars indicate the standard errors $(n=3)$. Significant differences at $P=0.05\left(^{*}\right)$ within the time after harvesting are indicated by letters.
$0.858 \mathrm{mg} / 100 \mathrm{mg}$, respectively (Fig. 6). These results were similar to previous studies in which the result observed as $54 \%$ reduction in the quercetin monoglucoside content during curing and drying of the onions at $28^{\circ} \mathrm{C}$ for 10 days (Price and Rhodes 1997). On the contrary, it has been reported that the field curing of onion resulted in a significant increase in quercetin content compared to curing in the absence of sunlight (Mogren et al., 2007b). Forced curing did not exert an essential effect on both skin and peeled onion as the quercetin content was less as compared to the controlled sample.

\section{SUMMARY AND CONCLUSION}

The amount of quercetin glucosides did not show significant relations with the number of irrigation as external irrigation showed higher contents of quercetin glucosides compared to those were treated with different time irrigation. Considering the lifting time the quercetin glucoside content was not affected by early lifting with better storage conditions for onions with significant level of quercetin content. In this study it was observed that the outer scales had a relatively higher ratio of quercetin monoglucosides to diglucosides than inner scales and overall concentration of quercetin monoglucosides is less than diglucosides. Forced curing did not exert an essential effect on both skin and peeled onion as the quercetin content was less as compared to the controlled sample. At the same time, forced curing treatment improves storability of onion. Quercetin content was not detected almost in all studied onion varieties but the content of quercetin diglucosides was higher than those of monoglucosides in all the varieties. This indicates that the great variability in flavonoid contents seems mainly depends on genetic factors, type of cultivars and the practice used during the cultivations.

\section{ACKNOWLEDGMENTS}

This research was supported KU-Research Professor Program-2016, Konkuk University, Seoul, South Korea.

\section{Author contributions}

S.H.N.: Design, formulation and supervision of experiment with writing and review of manuscript. E.Y.K.: Collection of data and did field experiments. K.S.: HPLC work and statistical analysis of data.

\section{REFERENCES}

Beesk, N., H. Perner, D. Schwarz, E. George, L. W. Kroh and S. Rohn. 2010. Distribution of quercetin-3,4'-O-diglucoside, quercetin-4'$\mathrm{O}$-monoglucoside, and quercetin in different parts of the onion 
bulb (Allium cepa L.) influenced by genotype. Food Chem. 122: $566-571$

Bonaccorsi, P., C. Caristi, C. Gargiulli and U. Leuzzi. 2008. Flavonol glucosides in Allium species: A comparative study by means of HPLC-DAD-ESI-MS-MS. Food Chem. 107: 1668-1673.

Caridi, D., C. Trenerry, S. Rochfort, S. Duong, D. Laugher and R. Jones. 2007. Profiling and quantifying quercetin glucosides in onion (Allium cepa L.) varieties using capillary zone electrophoresis and high performance liquid chromatography. Food Chem. 105: 691-699.

Chope, G.A., K. Cools, J.P. Hammond, A.J. Thompson and L.A. Terry. 2012. Physiological, biochemical and transcriptional analysis of onion bulbs during storage. Ann. Bot. 109(4): 819-831.

Chu, Y. H., C. L. Chang and H. F. Hsu. 2000. Flavonoid content of several vegetables and their antioxidant activity. J. Sci. Food Agric. 80: 561-566.

Coolong, T. W. and W. M. Randle. 2003. Ammonium nitrate fertility levels influence flavour development in hydroponically grown 'Granex 33' onion. J. Sci. Food Agric. 83: 477-482.

Enciso, J., B. Wiedenfeld, J. Jifon and S. Nelson. 2009. Onion yield and quality response to two irrigation scheduling strategies. Sci. Hortic. 120: 301-305.

Fustos, Z. S. 2007. The role of the dry scale in the dormancy of onions (Allium cepa L.). Acta Hortic. 433: 445-446.

Grevsen, K. and J. N. Sorensen. 2004. Sprouting and yield in bulb onions (Allium cepa L.) As influenced by cultivar, plant establishment methods, maturity at harvest and storage conditions. J. Hortic. Sci. Biotechnol. 79: 877-884.

Grevsen, K. and J. N. Sorensen. 2004. Sprouting and yield in bulb onions (Allium cepa L.) as influenced by cultivar, plant establishment methods, maturity at harvest and storage conditions. J. Hortic. Sci. Biotechnol. 79: 877-884.

Griffiths, G., L. Trueman, T. Crowther, B. Thomas and B. Smith. 2002. Onions-a global benefit to health. Phyto. Res. 16: 603-615.

Häanninen, O. K., A. Kaartinen, L. Rauma, M. Nenonen, R. Töorröonen, S. Häakkinen, H. Adlercreutz and J. Laakso. 2000. Antioxidants in vegan diet and rheumatic disorders. Toxicology. 155: 45-53.

Hegarty, V. M., H. M. May and K. T. Khaw. 2000. Tea drinking and bone mineral density in older women. Am. J. Clin. Nutr. 71: 1003-1007.

Higashio, H., H. Hirokane, F. Sato, S. Tokuda and A. Uragami. 2005. Effect of UV irradiation after the harvest on the content of flavonoid in vegetables. Acta Hortic. 682: 1007-1012.

Hollman, P. C. H. and I. C. W. Arts. 2000. Flavonols, flavones and flavanols - Nature, occurrence and dietary burden. J. Sci. Food Agric. 80: 1081-1093.

Jang, M., A. Leonid, S. H. Nile, Y. S. Keum, H. Y. Kim and S. W Park. 2013. Ultrasound-assisted extraction of quercetin from onion solid wastes. Int. J. Food Sci. Technol. 48: 246-252.

Kempuraj, D., M. Castellani, C. Petrarca, S. Frydas, P. Conti, T. Theoharides and J. Vecchiet. 2006. Inhibitory effect of quercetin on tryptase and interleukin-6 release, and histidine decarboxylase mRNA transcription by human mast cell-1 cell line. Clin. Exp. Med. 6: 150-156.

Kevin, L., P. Ellen, G. Emanuel, T. Leslie and H. Andy. 2005. Quercetin in onion after heat-treatment simulating home preparation. J. Food Comp. Anal. 18: 571-581.

Kumar, S., M. Imtiyaz, A. Kumar and R. Singh. 2007. Response of onion (Allium cepa L.) to different levels of irrigation water. Agric.
Water Manage. 89: 161-166.

Ko, E. Y., S. H. Nile, K. Sharma, G. H. Li and S. W. Park. 2015. Effect of different exposed lights on quercetin and quercetin glucoside content in onion (Allium cepa L.). Saudi J. Biol. Sci. 22: 398-403.

Lee, S. U., J. H. Lee, S. H. Choi, J. S. Lee, M. O. Kameyama, N. Kozukue, C. E. Levin and M. Friedman. 2008. Flavonoid content in fresh, home-processed, and light-exposed onions and in dehydrated commercial onion products. J. Agric. Food Chem. 56: 8541-8548.

Lombard, K., E. Peffley, E. Geoffriau, L. Thompson and A. Herring. 2005. Quercetin in onion (Allium cepa L.) after heat-treatment simulating home preparation. J. Food Comp. Anal. 18: 571-581.

Mogren, L. M., M. E. Olsson and U. E. Gertsson. 2006. Quercetin content in field-cured onions (Allium cepa L.): Effects of cultivar, lifting time, and nitrogen fertilizer level. J. Agric. Food Chem. 54: 6185-6191.

Mogren, L. M., M. E. Olsson and U. E. Gertsson. 2007a. Effects of cultivar, lifting time and nitrogen fertiliser level on quercetin content in onion (Allium cepa L.) at lifting. J. Sci. Food Agric. 87: 470-476.

Mogren, L. M., M. E. Olsson and U. E. Gertsson. 2007b. Quercetin content in stored onions (Allium cepa L.): Effects of storage conditions, cultivar, lifting time and nitrogen fertilizer level. J. Sci. Food Agric. 87: 1595-1602.

Nile, S. H. and S. W. Park. 2013. Total phenolics, antioxidant and xanthine oxidase inhibitory activity of three colored onions (Allium cepa L.). Front. Life Sci. 7: 224-228.

Pejic, B., J. Gvozdanovic-Varga, A.I. Milic, S. Cupina, D. Krstic and B. Cupina. 2011. Effect of irrigation schedules on yield and water use of onion (Allium cepa L.). Afr. J. Biotechnol. 10(14): 26442652.

Price, K. R. and Rhodes, M. J. C. 1997. Analysis of the major flavonol glycosides present in four varieties of onion (Allium cepa) and changes in composition resulting from autolysis. J. Agric. Food Chem. 74: 331-339.

Randle, W. M. 2000. Increasing nitrogen concentration in hydroponic solutions affects onion flavor and bulb quality. J. Am. Soc. Hortic. Sci. 125: 254-259.

Rodríguez, G. B., R. E. M. Rodríguez and R. C. Díaz. 2008. Flavonoids in onion cultivars (Allium cepa L.). J. Food Sci. 73: C599-C605.

Sharma, K., S. H. Nile and S. W. Park. 2015. Importance of growth hormones and temperatures for physiological regulation of dormancy and sprouting in onions. Food Rev. Int. 32: 233-255.

Shon, M. Y., S. D. Choi, G. G. Kahng, S. H. Nam and N. J. Sung. 2004. Antimutagenic, antioxidant and free radical scavenging activity of ethyl acetate extracts from white, yellow and red onions. Food Chem. Toxicol. 42: 659-666.

Shock, C.C. and F.X. Wang. 2011. Soil water tension, a powerful measurement for productivity and stewardship. Sci. Hortic. 46 178-185.

Soobrattee, M. A., T. Bahorun and O. I. Aruoma. 2006. Chemopreventive actions of polyphenolic compounds in cancer. BioFactors. 27: 19-35.

Wright, P. J., D. G. Grant and C. M. Triggs. 2001. Effects of onion (Allium cepa) plant maturity at harvest and method of topping on bulb quality and incidence of rots in storage. N. Z. J. Crop Hortic. Sci. 29: 85-91.

Yoo, K. S., E. J. Lee and B. S. Patil. 2010. Quantification of quercetin glycosides in 6 onion cultivars and comparisons of hydrolysisHPLC and spectrophotometric methods in measuring total quercetin concentrations. J. Food Sci. 75(2): C160-165. 